\title{
An educational programme on dengue fever prevention and control for females in Jeddah high schools
}

N.K. Ibrahim, ${ }^{1,2}$ B. Abalkhail, ${ }^{1}$ M. Rady ${ }^{1}$ and H. Al-Bar ${ }^{1}$

$$
\begin{aligned}
& \text { برنامج تثقيفي حول الوقاية من حمى الضنك ومكافحته لدى الإناث في المدارس الثانوية في جدة }
\end{aligned}
$$

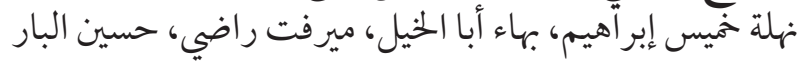

ABSTRACT A mass communication campaign was conducted at 20 randomly selected female high schools and 2 school supervision centres in Jeddah to improve knowledge, attitudes and practices of students, teachers and supervisors about dengue fever. A total of 5977 pre- and post-intervention questionnaires were completed and the intervention was conducted using lectures and audiovisual aids. A marked improvement in all areas of knowledge, attitudes and practices was observed after the programme in all groups. Students obtained the highest improvement in mean knowledge scores after the programme compared to the other 2 groups. There is a need to expand such programmes to all Jeddah schools.

Programme éducatif sur la lutte contre la dengue destiné aux jeunes filles des établissements d'enseignement secondaire de Djeddah

RÉSUMÉ Une campagne de communication de masse a été menée dans 20 établissements d'enseignement secondaire pour jeunes filles choisis au hasard et 2 centres d'inspection scolaire de Djeddah, afin d'améliorer les connaissances, les attitudes et les pratiques des élèves, des professeurs et des inspecteurs concernant la dengue. Au total, 5977 questionnaires ont été complétés avant et après l'intervention qui a été réalisée par le biais de conférences et de moyens audiovisuels. Après le programme, on a observé une nette amélioration des connaissances, des attitudes et des pratiques dans tous les domaines et dans tous les groupes. Les scores moyens relatifs aux connaissances ont augmenté de façon plus importante dans le groupe des élèves que dans les deux autres groupes. II est nécessaire d'élargir ce programme à tous les établissements scolaires de Djeddah.

${ }^{1}$ Department of Family and Community Medicine, King Abdul-Aziz University, Jeddah, Saudi Arabia (Correspondence to N.K. Ibrahim: nahlakhamis@yahoo.com).

${ }^{2}$ Department of Epidemiology, High Institute of Public Health, University of Alexandria, Alexandria, Egypt.

Received: 28/01/07; accepted: 15/05/07

المجلة الصحية لشرق المتو سط، منظمة الصحة العالمية، المجلد الخامس عشر، العدد 0، 9 ب. 


\section{Introduction}

Dengue fever (DF) and dengue haemorrhagic fever (DHF) represent great challenges to public health at a world level. The World Health Organization (WHO) reported that about 2.5 billion people $(40 \%$ of the world's population) are at risk of developing the disease $[1,2]$. Epidemics of dengue-like disease were reported from the Arabian peninsula in the late 19th century, affecting many major cities such as Aden, Jeddah, Mecca and Medina [3,4].

DF has recently re-emerged as a major international health problem with an expanded geographic distribution and the potential to cause major epidemics $[1,5]$. Associated with the rise of DF has been an increase in associated mortality [5]. It continues to be a significant health problem in the western region of Saudi Arabia [3] and a study from Jeddah in 2006 confirmed the endemic occurrence of DF in the region [4]. Millions of Muslim pilgrims from all over the world transit through Jeddah, creating a high-risk for transmission of infectious diseases, including DF, among pilgrims and residents $[3,4]$.

The 55th World Health Assembly declared DF prevention and control a priority and urged Member States to develop sustainable intersectoral strategies [6]. In the absence of a vaccine, seroprophylaxis or specific treatment for the disease [2] the principal strategy is a sustainable integrated approach to prevention of transmission by controlling the principal vector, Aedes aegypti. This should be based more on community involvement to control mosquitoes in the domestic environment than on the use of chemicals [7]. Health education programmes involving different sectors in the community are important intervention tools to promote behaviour changes that lead to involving the community in controlling DF, particularly the vector [8]. To be successful, community-based strategies must be flexible and adapted to the local setting because of ecological, cultural and social differences between localities [9].

As DF represents an escalating health problem in Jeddah and since there is a lack of community-based health educational intervention strategies, an intervention programme for prevention and control is urgently needed. The aim of this study was to improve the knowledge, attitudes and practices of female high-school students, teachers and supervisors towards DF.

\section{Methods}

An intervention strategy with a mass communication campaign was conducted during the education year 2005-06. The fieldwork was carried out by 4th year medical students at the Department of Family and Community Medicine, King Abdul-Aziz University. In the preparatory phase of the study, students worked with their supervisors on questionnaire construction, message development and production of educational materials to be used during the programme.

\section{Sample}

The target population was female students, teachers and supervisors in high schools because control strategies for DF focus on good practice inside the home, which is mainly the responsibility of females. In addition, female students can be good health educators for their parents, especially their mothers.

A total of 20 girls' high schools in Jeddah governorate were selected (about 8\% of the total of 242): 16 government and 4 private schools. The schools were selected using a multistage, stratified, random sampling method from all districts of Jeddah 
using the proportional allocation technique. Students were selected using a multistage, stratified, random sampling method, taking into consideration type (private or government), geographic district (north, middle, south-east or south-west), speciality in which students were enrolled (literature or science) and grade (1st, 2nd or 3rd year).

The total number of students who participated in the pre-intervention test was 2693: $84.4 \%$ were enrolled in government schools while the rest were in private schools. About one-quarter of the students came from each of the 4 Jeddah districts. About two-fifths $(39.1 \%)$ were enrolled in the science section and $34.2 \%$ in literature while $26.7 \%$ were in the 1 st year and did not have a specialty.

All teachers available in the selected schools on the days of interview who agreed to participate in the study were included ( $n$ $=356$ ). In addition, 2 randomly selected female supervision centres (out of 4 Jeddah centres) were included in the study and all schoolteacher supervisors who were available on the day of interview and agreed to participate $(n=115)$ were also enrolled.

\section{Intervention and data collection}

The design and implementation of the health education intervention were conducted in 5 stages: formative research, developing recommendations for behaviour change, developing educational messages, and developing and producing educational materials [1]. Implementation and evaluation of the health education programme was done in 3 stages: completion of the pre-intervention questionnaire (pre-test); delivery of the health education intervention; and completion of the post-intervention questionnaire (post-test).

\section{Pre-intervention test}

On enrolment, each participant completed a questionnaire. A total of 3164 people completed the pre-test questionnaire (2693 students, 356 teachers, 115 supervisors).

The student questionnaire collected personal and sociodemographic data, e.g. district, type of school, age of student, education grade, etc. For teachers and supervisors personal and sociodemographic data were also gathered.

For all groups, the variables needed to gather baseline data on participants' knowledge, attitudes and practices towards DF were collected, as follows:

- To assess participants' knowledge about DF before the programme, the questionnaire included 30 questions with multiple-choice answers. Knowledge variables inquired about types, causative agents, incubation period and mode of transmission of DF; the name of the principle mosquito vector ( $A$. aegypti) and the most important times of transmission and breeding sites; clinical picture, complications and diagnosis of $\mathrm{DF}$; and the basic steps needed for DF prevention and control, including the telephone number for reporting the presence of stagnant water.

- Participants' attitudes were determined with 8 questions asking whether they agreed (yes or no) about: DF's importance as a public health problem in Jeddah; the importance of inquiring about patients' condition and movements; the importance of searching for the presence of mosquito vectors in homes; and other preventive and control measures.

- Self-reported practices (positive or negative) were assessed with 12 items. Positive practices included going to the doctor when they suspected a case of DF; removing or reporting stagnant water; use of mosquito repellents and home insecticides; and wearing protective clothing. Negative practices included: 
doing nothing in case of observation of stagnant water.

\section{Intervention}

The health education intervention covered the most important issues related to DF and the answers to all the questions in the questionnaires and was delivered through a number of strategies.

The study sample was given a health education and discussion session which started with a 20-minute lecture presentation in Arabic, supported by audiovisual aids. The lecture included information about the magnitude and importance of DF in Jeddah; the cycle of infection; symptoms, signs and complications of the disease; practices that predispose to occurrence of the disease; and preventive and control measures. A film and cartoon were also shown about how people catch DF and methods of prevention and control. At the end each participant was requested to spread the education message about DF control to family and friends.

After delivering the sessions to the research sample, they were then delivered to the rest of the school students and teachers, supervisors and school administrators.

In addition to the health education sessions, information about the disease was extensively distributed to the study sample to stimulate changes in practice. Materials included brochures, small gifts with DF educational messages, posters, stickers and a CD-ROM containing the lecture and film sessions. In addition, many educational models were constructed. One of these was large and illustrated the environments which favour breeding of the mosquito vectors of DF and examples of hygienic environments which discourage breeding.

Costs of copying materials were covered by a grant from a national nongovernmental organization (Zamzam). Some materials were compiled by students themselves.

\section{Post-intervention test}

The pre-test questionnaire to students and teachers was re-administered 1 week after the health education sessions, and the results were compared. Overall 2813 subjects $(88.9 \%)$ responded in the post-test, including 2433 students (90.3\%), 310 (87.1\%) teachers and 70 supervisors $(60.9 \%)$.

\section{Statistical analysis}

The collected data were coded, reviewed and entered into the computer programme SPSS, version 13.

Knowledge and practice scores were calculated as follows. The knowledge scale consisted of 30 items. Responses to each item consisted of multiple choices scored 1 for a correct answer and 0 for incorrect or don't know answers. The total knowledge score ranged from 0 to 30 and was classified as: satisfactory $[>$ mean + standard deviation (SD)]; fair (mean $-\mathrm{SD}$ to mean $+\mathrm{SD}$ ); or poor $(<$ mean $-\mathrm{SD})$. The practice scale consisted of 12 items, each item scored 1 for positive practice and 0 for no positive practice or negative practice. The same score as that of knowledge was calculated. The percentage difference in knowledge and practice scores for the 3 groups before and after the intervention was calculated.

The statistical analysis was conducted using the chi-squared test, nonparametric Wilcoxon signed-rank test for 2 related samples and 1-way ANOVA test. The least significant difference was calculated. All results were deemed statistically significant at $P<0.05$.

\section{Results}

Table 1 shows the results of the Wilcoxon signed-rank test of changes in mean knowledge and practice scores of students, teachers and supervisors before and after the 
programme. There was a significant improvement in the mean knowledge score of all 3 study groups after the health education intervention. The largest improvement was among students, whose mean pre-test knowledge score of 10.08 (SD 4.96) increased significantly post-test to 25.58 (SD 3.24) $(z=42.66 ; P<0.001)$. Similar changes were found among both teachers and supervisors. There were also significant improvements in the mean practice scores for all groups.

In the pre-test, the knowledge scores were poor, fair and satisfactory for $42.3 \%$, $57.6 \%$ and $0.1 \%$ of the total sample respectively. These rates improved in the post-test to $0.2 \%, 42.8 \%$ and $57.0 \%$ respectively. Regarding the practice scores, the corresponding rates in the pre-test were $32.6 \%$, $58.0 \%$ and $9.4 \%$, rising to $4.6 \%, 49.1 \%$ and $46.3 \%$ respectively in the post-test. Fair and satisfactory scores were combined (Table 2) which showed that $42.3 \%$ of the study sample obtained a poor knowledge score in the pre-test, which declined to $0.2 \%$ in the post-test $(P<0.001)$. Regarding practices, the rate of both fair and satisfactory scores among the total sample increased from $67.4 \%$ before the programme to $95.4 \%$ after the campaign $(P<0.001)$.

Table 3 illustrates the percentage difference between participant's knowledge before and after the educational programme. 1-way ANOVA test showed that the highest difference was for students $(274.5 \%)$ followed by teachers (186.4\%) and supervisors $(141.3 \%)$. The difference was highly significant between the 3 groups $(F=9.64$, $P<0.0001)$. The percentage difference for students' knowledge was significantly different from teachers' $(P<0.001)$ and supervisors' $(P<0.05)$ by the least significant difference test. On the other hand, no statistically significant differences were found for practice percentage differences of students, teachers and supervisors pre- and post-test $(P>0.05)$.

The attitudes of the target group were also altered after the health education programme. Table 4 shows that before the intervention $83.8 \%$ of the total sample agreed that DF was an important public health problem in Jeddah. This rate increased significantly to $95.7 \%$ after the intervention

\begin{tabular}{|c|c|c|c|}
\hline $\begin{array}{l}\text { Questionnaire section/ } \\
\text { group }\end{array}$ & $\begin{array}{c}\text { Pre-test } \\
\text { Mean (SD) }\end{array}$ & $\begin{array}{c}\text { Post-test } \\
\text { Mean (SD) }\end{array}$ & $z^{a}, P$-value \\
\hline \multicolumn{4}{|l|}{ Knowledge } \\
\hline Students & $10.08(4.96)$ & $25.58(3.24)$ & $42.66,<0.001$ \\
\hline Teachers & $12.62(5.44)$ & $25.52(3.72)$ & $14.74,<0.001$ \\
\hline Supervisors & $12.76(5.77)$ & $25.77(2.64)$ & $6.00,<0.001$ \\
\hline Total & $10.57(5.14)$ & $25.57(3.28)$ & $45.54,<0.001$ \\
\hline \multicolumn{4}{|l|}{ Practices } \\
\hline Students & $8.36(2.70)$ & $10.92(1.52)$ & $32.50,<0.001$ \\
\hline Teachers & $8.14(2.91)$ & $10.40(1.71)$ & $10.37,<0.001$ \\
\hline Supervisors & 8.55 (2.39) & $10.23(1.56)$ & $3.50,<0.001$ \\
\hline Total & $8.34(2.71)$ & $10.85(1.56)$ & $34.30,<0.001$ \\
\hline
\end{tabular}

aWilcoxon signed-rank test.

$S D=$ standard deviation. 


\begin{tabular}{|c|c|c|c|c|c|}
\hline \multirow{2}{*}{$\begin{array}{l}\text { Questionnaire section/ } \\
\text { score }\end{array}$} & \multicolumn{2}{|c|}{ Pre-test } & \multicolumn{2}{|c|}{ Post-test } & \multirow[t]{2}{*}{$\chi^{2}, P$-value } \\
\hline & No. & $\%$ & No. & $\%$ & \\
\hline \multicolumn{6}{|l|}{ Knowledge } \\
\hline Poor score & 1338 & 42.3 & 6 & 0.2 & $512.43,<0.001$ \\
\hline Fair/satisfactory score & 1826 & 57.7 & 2807 & 99.8 & \\
\hline Total & 3164 & 100.0 & 2813 & 100.0 & \\
\hline \multicolumn{6}{|l|}{ Practices } \\
\hline Poor score & 1031 & 32.6 & 130 & 4.6 & $743.99,<0.001$ \\
\hline Fair/satisfactory score & 2133 & 67.4 & 2683 & 95.4 & \\
\hline Total & 3164 & 100.0 & 2813 & 100.0 & \\
\hline
\end{tabular}

$\left(\chi^{2}=223.7 ; P<0.001\right)$. Regarding attitudes towards preventive measures, $79.9 \%$ of the pre-test sample agreed that it is important to use mosquito repellents; this increased to $97.9 \%$ post-test $\left(\chi^{2}=466.2 ; P<0.001\right)$.

\section{Discussion}

The results of the present school-based mass communication campaign showed a significant positive impact of the pro- gramme on knowledge and practices related to DF prevention among the target groups. In term of knowledge, the results revealed a significant increase in students', teachers' and supervisors' knowledge. The highest knowledge gain (highest percentage difference) was obtained by students. This may be because students had the lowest mean knowledge scores in the pre-test compared with the other 2 groups or because the recall memory in this age group is greater than the

\begin{tabular}{|c|c|c|c|}
\hline $\begin{array}{l}\text { Questionnaire section/ } \\
\text { group }\end{array}$ & $\begin{array}{c}\% \text { difference } \\
\text { post-test-pre-test } \\
\text { mean score }\end{array}$ & $95 \% \mathrm{Cl}$ & $F, P$-value \\
\hline \multicolumn{4}{|l|}{ Knowledge } \\
\hline Students & $274.5^{\mathrm{a}}$ & 258.9-290.1 & $9.64,<0.0001$ \\
\hline Teachers & 186.4 & $151.9-220.8$ & \\
\hline Supervisors & 141.3 & $105.8-176.9$ & \\
\hline Total & 262.2 & $248.4-276.9$ & \\
\hline \multicolumn{4}{|l|}{ Practices } \\
\hline Students & 65.2 & $59.2-71.2$ & $1.31,0.27$ \\
\hline Teachers & 67.0 & $48.3-85.8$ & \\
\hline Supervisors & 29.4 & $13.5-45.3$ & \\
\hline Total & 64.9 & $59.2-70.5$ & \\
\hline
\end{tabular}

a Percentage difference of students' knowledge was significantly different from teachers $(P<0.001)$, and supervisors $(P<0.05)$.

$\mathrm{Cl}=$ confidence interval.

المجلة الصحية لشرق المتوسط، منظمة الصحة العالمية، المجلد الخامس عشر، العدد 0، 9. 
other 2 groups. Results of the evaluation of an educational module for schoolchildren in Honduras also showed a significant increase in both the students' and teachers' knowledge after an educational module on DF and A. aegypti [10]. The results of the present study also agree with the results of research conducted to assess the effectiveness of a DF community-based programme in 2 Thai villages which revealed improve- ments in knowledge of their target group after the programme [11]. Furthermore, our results agree with those of a short-term community-based DF campaign in Taiwan [12].

The health education programme in our study improved the percentage of participants with satisfactory knowledge scores from $0.1 \%$ pre-test to $57.0 \%$ post-test. These results agree with those from Indo-

\begin{tabular}{|c|c|c|c|c|c|}
\hline \multirow{2}{*}{$\begin{array}{l}\text { Agree about the } \\
\text { importance of: }\end{array}$} & \multicolumn{2}{|c|}{ Pre-test } & \multicolumn{2}{|c|}{ Post-test } & \multirow[t]{2}{*}{$\chi^{2}, P$-value } \\
\hline & No. & $\%$ & No. & $\%$ & \\
\hline \multicolumn{6}{|c|}{$\begin{array}{l}\text { Dengue fever as a health } \\
\text { problem in Jeddah }\end{array}$} \\
\hline Yes & 2650 & 83.8 & 2692 & 95.7 & $223.7,<0.001$ \\
\hline No & 514 & 16.2 & 121 & 4.3 & \\
\hline \multicolumn{6}{|c|}{$\begin{array}{l}\text { Inquiring about patients' } \\
\text { conditions and movements }\end{array}$} \\
\hline Yes & 2669 & 84.4 & 2679 & 95.2 & $187.2,<0.001$ \\
\hline No & 495 & 15.6 & 134 & 4.8 & \\
\hline \multicolumn{6}{|c|}{$\begin{array}{l}\text { Taking laboratory samples } \\
\text { from patients }\end{array}$} \\
\hline Yes & 2444 & 77.2 & 2627 & 93.4 & $301.7,<0.001$ \\
\hline No & 720 & 22.8 & 186 & 6.6 & \\
\hline \multicolumn{6}{|c|}{$\begin{array}{l}\text { Making mosquito searches } \\
\text { at home }\end{array}$} \\
\hline Yes & 2731 & 86.3 & 2703 & 96.1 & $172.3,<0.001$ \\
\hline No & 433 & 13.7 & 110 & 3.9 & \\
\hline \multicolumn{6}{|c|}{$\begin{array}{l}\text { Spraying insecticides at } \\
\text { home }\end{array}$} \\
\hline Yes & 2809 & 88.8 & 2732 & 97.1 & $153.2,<0.001$ \\
\hline No & 355 & 11.2 & 81 & 2.9 & \\
\hline \multicolumn{6}{|c|}{ Using mosquito repellents } \\
\hline Yes & 2529 & 79.9 & 2753 & 97.9 & $466.2,<0.001$ \\
\hline No & 635 & 20.1 & 60 & 2.1 & \\
\hline \multicolumn{6}{|c|}{ Installing windows nets } \\
\hline Yes & 2536 & 80.2 & 2676 & 95.1 & $299.3,<0.001$ \\
\hline No & 628 & 19.8 & 137 & 4.9 & \\
\hline \multicolumn{6}{|c|}{$\begin{array}{l}\text { Removing or covering } \\
\text { stagnant water collection }\end{array}$} \\
\hline Yes & 2918 & 92.2 & 2799 & 99.5 & $189.5,<0.001$ \\
\hline No & 246 & 7.8 & 14 & 0.5 & \\
\hline Total & 3164 & 100.0 & 2813 & 100.0 & \\
\hline
\end{tabular}


nesia where the corresponding rates among workers at 2 textile factories in Bandung were $0.3 \%$ pre-test and $8.4 \%$ post-test after 18 months [13]. The higher rate obtained post-test in our study may be due to differences in the type of target population or the difference in the duration after which the post-test was conducted. A study that evaluated knowledge, attitudes and practices concerning DF in rural and urban resettlement areas of New Delhi reported that a high level of DF awareness was observed among the respondents, which could be attributed to the health education and information campaign of the audiovisual media and health care personnel. Knowledge about DF was fair to good, particularly among urban residents [14].

People do not change behaviour all of a sudden and remain "changed" from that moment onwards. Rather, they move through stable stages from becoming aware to becoming informed, becoming convinced, deciding to take action, taking action, repeating that action and finally maintaining the action [1]. This concept agrees with the results of our study which revealed a marked improvement in knowledge that was higher than the improvement in practices. Other studies have also shown that knowledge takes a shorter time to change compared to practices. A DF educational programme conducted in Puerto Rico in 2002 in the form of televised public service announcements and posters, elementary and preschool educational programmes, and an exhibit at the children's museum reported high levels of awareness and some behaviour change [15]. A study among Venezuelan schoolchildren aged 8-16 years found that by using a game as an educational strategy they acquired greater knowledge and skills about DF than using a theoretical programme alone [16]. A study conducted in Mexico, found that an education intervention was successful in stimulating changes in both knowledge and behaviour [9]. A study of a DF educational programme in Grenada in 2005 found that although many people had knowledge and were familiar with DF and mosquitoes, their knowledge of the important relationships of mosquitoes and human behaviour with disease transmission was incomplete [17]. A study that aimed to identify changes in knowledge and practices to prevent DF using educational aids in a study area and a control area in Brazil from 1999 to 2001 found that there was improvement in knowledge and practices after the programme in the study area only [18].

Our study showed improvements in all areas of knowledge, attitudes and practices of the study group towards DF, which agrees with the results of a quasi-experimental study reported from Havana, Cuba, in 2005, which found significant changes in knowledge, attitudes and practices in the intervention population compared to the control group after the intervention [6]. Our results also agree with those of Swaddiwudhipong et al. from Thailand [19].

In Jeddah, with its high pilgrim traffic all year around, it is necessary to promote DF control as a priority. The educational interventions in our study conducted for this purpose and directed to female highschool students, teachers and supervisors was very successful in raising their awareness with respect to the problem of DF, and in encouraging members to change their practices. Students had the highest ability to gain knowledge and it was reflected in changing practices. Changes in knowledge were greater than changes in practice which reflects the fact that these changes take more time and need sustained education. Longer term changes in knowledge and practices should be studied by carrying out post-post-tests and comparing knowledge, attitudes and practices in both tests 


\section{Acknowledgements}

The authors would like to thank the 4th year medical students for their efforts during the survey. We would like to thank Professor Adnan Al Bar, and Zazmam NGO for their efforts and funding for copying the educa- tional materials. We we would also like to express our deepest appreciation to all those at the Ministry of Education who facilitated the conduct of the work. Finally, we would like thank all those who participated in the study.

\section{References}

1. Parks W, Lloyd L, eds. Planning social mobilization and communication for dengue fever prevention and control: a stepby-step guide. Geneva, World Health Organization Mediterranean Centre for Vulnerability Reduction and the UNICEF/ UNDP/World Bank/WHO Special Programme for Research and Training in Tropical Diseases, 2004 (WHO/CDS/ WMC/2004.2).

2. Samuel PP, Tyagi BK. Diagnostic methods for detection \& isolation of dengue viruses from vector mosquitoes. Indian journal of medical research, 2006, 123(5):615-28.

3. Fakeeh M, Zaki AM. Virologic and serologic surveillance for dengue fever in Jeddah, Saudi Arabia, 1994-1999. American journal of tropical medicine and hygiene, 2001, 65(6):764-7.

4. Ayyub $\mathrm{M}$ et al. Characteristics of dengue fever in a large public hospital, Jeddah, Saudi Arabia. Journal of Ayub Medical College, Abbottabad, 2006, 18(2):9-13.

5. Ong A et al. Fatal dengue hemorrhagic fever in adults during a dengue epidemic in Singapore. International journal of infectious diseases, 2007, 11:263-7.

6. Sanchez $L$ et al. Intersectoral coordination in Aedes aegypti control. A pilot project in Havana City, Cuba. Tropical medicine and international health, 2005, 10(1):82-91.

7. Espinoza-Gómez F, Hernández-Suárez $\mathrm{CM}$, Coll-Cárdenas R. Educational campaign versus malathion spraying for the control of Aedes aegypti in Colima, Mexico. Journal of epidemiology and community health, 2002, 56:148-52.

8. Claro LB, Tomassini HC, Rosa ML. Prevenção e controle do dengue: uma revisão de estudos sobre conhecimentos, crenças e práticas da população [Dengue prevention and control: a review of studies on knowledge, beliefs, and practices]. Cadernos de saúde pública, 2004, 20(6):1447-57.

9. Lloyd LS et al. The design of a community-based health education intervention for the control of Aedes aegypti. American journal of tropical medicine and hygiene, 1994, 50(4):401-11.

10. Avila Montes GA et al. Evaluación de un módulo escolar sobre dengue y Aedes aegypti dirigido a escolares en Honduras [Evaluation of an educational module on dengue and Aedes aegypti for schoolchildren in Honduras]. Revista panamericana de salud pública, 2004, 16(2):84-94.

11. Therawiwat $\mathrm{M}$ et al. Community-based approach for prevention and control of dengue hemorrhagic fever in Kanchanaburi Province, Thailand. Southeast Asian journal of tropical medicine and public health, 2005, 36(6):1439-49.

12. Pai HH, Hong YJ, Hsu EL. Impact of a short-term community-based cleanliness campaign on the sources of dengue vectors: an entomological and human behav- 
ior study. Journal of environmental health, 2006, 68(6):35-9.

13. Beckett $\mathrm{CG}$ et al. Enhancing knowledge and awareness of dengue during a prospective study of dengue fever. Southeast Asian journal of tropical medicine and public health, 2004, 35(3):614-7.

14. Gupta P, Kumar P, Aggarwal OP. Knowledge, attitude and practices related to dengue in rural and slum areas of Delhi after the dengue epidemic of 1996. Journal of communicable diseases, 1998, 30(2):107-1.

15. Winch PJ et al. Community-based dengue prevention programs in Puerto Rico: impact on knowledge, behavior, and residential mosquito infestation. American journal of tropical medicine and hygiene, 2002, 67(4):363-70.

16. Vivas E, Guevara De Sequeda M. Un juego como estrategia educativa para el control de Aedes aegypti en escolares venezolanos [A game as an educational strategy for the control of Aedes aegypti in Venezuelan schoolchildren]. Revista panamericana de salud pública, 2003, 14(6):394-401.

17. Panagos A et al. Dengue in Grenada. Revista panamericana de salud pública, 2005, 17(4):225-9.

18. Chiaravalloti Neto $F$ et al. Controle do vetor do dengue e participacao da comunidade em Catanduva, Sao Paulo, Brasil [Dengue vector control and community participation in Catanduva, São Paulo State, Brazil]. Cadernos de saúde pública, 2003, 19(6):1739-49.

19. Swaddiwudhipong $W$ et al. A survey of knowledge, attitude and practice of the prevention of dengue hemorrhagic fever in an urban community of Thailand. Southeast Asian journal of tropical medicine and public health, 1992, 23(2):20711.

\section{DengueMet}

DengueMet is the World Health Organization's central data management system for the global epidemiological and virological surveillance of dengue fever (DF) and dengue haemorrhagic fever (DHF) created in partnership with WHO Regional and Country Offices, Ministries of Heath, WHO Collaborating Centres and laboratories.

The key objective of Dengueret is to provide a standard platform for sharing current surveillance data in order to detect and monitor incidence and trends of DF and DHF. DengueMet also provides unrestricted access to useful information that can help public health professionals with advance warning of epidemics to improve preparedness, case management, and reduce fatality rates.

Further information is available at: http://apps.who.int/globalatlas/ default.asp 